\title{
Functional Brain Changes Underlying Irritability in Premanifest Huntington's Disease
}

\author{
Jan Van den Stock, ${ }^{1,2} *$ François-Laurent De Winter, ${ }^{1,2}$ Rawaha Ahmad, ${ }^{3,4}$ \\ Stefan Sunaert, ${ }^{3,5}$ Koen Van Laere, ${ }^{3,4}$ Wim Vandenberghe, ${ }^{6}$ and \\ Mathieu Vandenbulcke ${ }^{1,2}$ \\ ${ }^{1}$ Department of Neurosciences, KU Leuven, Psychiatry Research Group, Leuven, Belgium \\ ${ }^{2}$ Old Age Psychiatry Department, University Hospitals Leuven, Leuven, Belgium \\ ${ }^{3}$ Department of Imaging and Pathology, KU Leuven, Leuven, Belgium \\ ${ }^{4}$ Division of Nuclear Medicine and Molecular Imaging, University Hospitals Leuven, Leuven, \\ Belgium \\ ${ }^{5}$ Department of Radiology, University Hospitals Leuven, Leuven, Belgium \\ ${ }^{6}$ Department of Neurology, University Hospitals Leuven, Leuven, Belgium
}

\begin{abstract}
The clinical phenotype of Huntington's disease (HD) consists of motor, cognitive and psychiatric symptoms, of which irritability is an important manifestation. Our aim was to identify the functional and structural brain changes that underlie irritability in premanifest HD (preHD). Twenty preHD carriers and 20 gene-negative controls from HD families took part in the study. Although the 5-year probability of disease onset was only 11\%, the preHD group showed striatal atrophy and increased clinical irritability ratings. Functional MRI was performed during a mood induction experiment by means of recollection of emotional (angry, sad, and happy) and neutral autobiographical episodes. While there were no significant group differences in the subjective intensity of the emotional experience, the preHD group showed increased anger-selective activation in a distributed network, including the pulvinar, cingulate cortex, and somatosensory association cortex, compared to gene-negative controls. Pulvinar activation during anger experience correlated negatively with putaminal grey matter volume and positively with irritability ratings in the preHD group. In addition, the preHD group showed a decrease in angerselective activation in the amygdala, which correlated with putaminal and caudate grey matter volume. In conclusion, compared to gene-negative controls, anger experience in preHD is associated with activity changes in a distributed set of regions known to be involved in emotion regulation. Increased activity is related to behavioral and volumetric measures, providing insight in the pathophysiology of early neuropsychiatric symptoms in preHD. Hum Brain Mapp 36:2681-2690, 2015. @ 2015 Wiley Periodicals, Inc.
\end{abstract}

Key words: pulvinar; gyrus cingulus; amygdala; emotions; affective symptoms; aggression

Conflict of interest: None of the authors has any conflict of interest to declare.

Contract grant sponsor: Fonds Wetenschappelijk OnderzoekVlaanderen (J.VdS.); Contract grant sponsor: FWO Research Grant; Contract grant number: 1.5.072.13N.

*Correspondence to: Jan Van den Stock, O\&N II Bus 1027, Herestraat 49, 3000 Leuven, Belgium.
E-mail: jan.vandenstock@med.kuleuven.be

Received for publication 15 December 2014; Revised 16 March 2015; Accepted 18 March 2015.

DOI: 10.1002/hbm.22799

Published online 8 April 2015 in Wiley Online Library (wileyonlinelibrary.com). 


\section{INTRODUCTION}

Huntington's disease (HD) is a dominantly inherited, fatal neurodegenerative disorder caused by a CAG repeat expansion in the HTT gene on chromosome 4. In the western world, the prevalence of HD is 5-10 per 100,000, making it the third most prevalent neurodegenerative disease after Alzheimer's disease and Parkinson's disease. The principal neuropathological change is the loss of striatal medium spiny neurons, and to a lesser degree neuronal loss in neocortex, hippocampus, and thalamus. Progression of the disease is associated with more widespread neuronal loss and brain atrophy [Vonsattel, 2008]. HD is typically characterized by a triad of symptoms and signs, composed of a movement disorder including chorea, cognitive deterioration, and behavioral disturbances. Irritability is among the earliest and most frequent psychiatric symptoms and is associated with inflexibility, perseverative preoccupations, verbal outbursts, and aggression [Craufurd et al., 2001]. It strongly contributes to the need for inpatient treatment [Wheelock et al., 2003]. Clinical disease onset is conventionally defined by the onset of the movement disorder. However, neuropsychiatric symptoms are often already present before the onset of motor symptoms. Carriers of the Huntington mutation that do not display motor disturbance are referred to as premanifest HD (preHD) subjects [Ross et al., 2014]. Recently, research has increasingly focused on the premanifest stage, as this might benefit the development of therapeutic interventions [Tabrizi et al., 2013]. Irritability has been reported in up to $73 \%$ of preHD subjects [van Duijn et al., 2007].

Little is known about the brain changes that underlie neuropsychiatric symptoms in preHD. One study examined irritability in preHD by giving negative false feedback in a size discrimination task. The results showed reduced activation of the amygdala as well as reduced coupling between amygdala and medial prefrontal cortex in the preHD group compared to healthy controls [Kloppel et al., 2010]. This may reflect an abnormal recognition of the own emotional state in preHD, a finding that has been reported in manifest HD [Ille et al., 2011; Reedeker et al., 2012] and may also underlie impaired recognition of emotions in others [de Gelder et al., 2008; Henley et al., 2012; Ille et al., 2011; Kret et al., 2010; Trinkler et al., 2013]. In this study, we build on these findings and focus on the experiential aspect of emotions, that is, "feelings" [Damasio and Carvalho, 2013].

The main goal of this study was to examine the pathophysiology underlying irritability in preHD. We, therefore, measured brain activation associated with feelings of anger in preHD and gene-negative controls from HD families (Gene-Neg Ctrls). The neural circuitry underlying anger experience in normal subjects comprises a distributed set of cortical and subcortical regions, of which the pulvinar, cingulate cortex, lenticular nucleus, insula, frontal cortices, cerebellum, and (para)hippocampal regions have been consistently reported [Damasio and Carvalho,
2013; Denson et al., 2009; Fabiansson et al., 2012; Pawliczek et al., 2013; Vytal and Hamann, 2010]. It has been proposed that areas containing interoceptive topographic maps like the insula underlie the subjective experience of emotional bodily states (feelings), while the anterior cingulate cortex (ACC) generates emotion-related actions [Damasio and Carvalho, 2013]. Interestingly, thalamic, cerebellar, and cingular metabolic abnormalities have also been reported in preHD [Feigin et al., 2007]. We investigated group differences in the functional neuroanatomy of experiencing anger and related this to structural brain changes and clinical irritability.

\section{MATERIALS AND METHODS}

\section{Participants}

The study was approved by the Ethical Committee of University Hospitals Leuven (ML8040) and subjects' consent was obtained according to the Declaration of Helsinki. All participants were recruited through the department of Human Genetics of University Hospitals Leuven following predictive genetic testing for HD. After complete description of the study to the subjects, written informed consent was obtained. Twenty premanifest carriers of the HD mutation (CAG repeat length of 40 or more; absence of visible chorea and Unified Huntington's Disease Rating Scale (UHDRS) motor score <6) [Tabrizi et al., 2009] participated as well as twenty gene-negative controls (GeneNeg Ctrls) from HD families (CAG repeat length of 35 or less). We included Gene-Neg Ctrls as a control group to match both groups regarding the distress of growing up with affected and at-risk family members and undergoing predictive genetic testing for HD [Julien et al., 2007]. Demographic data are summarized in Table I. All participants underwent motor assessment based on the motor subscale of the Unified Huntington's Disease Rating Scale [Huntington Study Group, 1996], administered by a trained physician. Cognitive evaluation consisted of a battery of commonly used neuropsychological tests. Mood evaluation included BDI [Beck et al., 1961] and STAI [Spielberger et al., 1970] (Table I). To assess neuropsychiatric symptoms associated with HD, the Problem Behaviors Assessment for HD (PBA-HD) [Craufurd et al., 2001] was administered to all participants by a trained physician who was unaware of the genetic status of the interviewee. The PBA-HD consists of a 36-item semistructured interview, with a three factor structure: Apathy, Irritability, and Depression.

\section{Experimental Stimuli and Paradigm}

One week prior to the MRI session, participants were instructed to select eight autobiographical events that were associated with intense emotions: two during which they felt angry, two during which they felt happy, two during 
TABLE I. Demographic, clinical, behavioral, and cognitive characteristics of premanifest Huntington's disease carriers and gene-negative controls

\begin{tabular}{|c|c|c|c|c|c|}
\hline \multirow[b]{2}{*}{ Characteristic } & \multicolumn{2}{|c|}{$\begin{array}{l}\text { Premanifest carriers of } \\
\text { Huntington mutation } \\
\qquad(N=20)\end{array}$} & \multicolumn{2}{|c|}{ Gene-Neg Ctrls $(N=20)$} & \multirow[b]{2}{*}{$P$} \\
\hline & $N$ & $\%$ & $N$ & $\%$ & \\
\hline \multirow[t]{2}{*}{ Gender (female) } & 13 & 65 & 10 & 50 & $0.52^{\mathrm{a}}$ \\
\hline & Mean & $\mathrm{SD}$ & Mean & $\mathrm{SD}$ & \\
\hline Age (years) & 36.7 & 8.0 & 38.4 & 14.4 & $0.64^{\mathrm{b}}$ \\
\hline CAG & 42.1 & 1.8 & 20.1 & 4.6 & $0.0010^{\mathrm{b} *}$ \\
\hline UHDRS_m & 2.7 & 1.9 & 1.8 & 1.2 & $0.10^{\mathrm{b}}$ \\
\hline 5yPDO & 0.11 & 0.16 & 0 & 0 & \\
\hline \multicolumn{6}{|l|}{ Mood } \\
\hline BDI & 5.8 & 6.1 & 4.2 & 5.4 & $0.50^{\mathrm{b}}$ \\
\hline STAI 1 & 43.4 & 9.3 & 44.5 & 4.6 & $0.58^{\mathrm{b}}$ \\
\hline STAI 2 & 45.1 & 7.2 & 47.5 & 4.2 & $0.21^{\mathrm{b}}$ \\
\hline PBA-HD Total & 11.2 & 11.1 & 4.7 & 4.3 & $0.023^{\mathrm{b} *}$ \\
\hline PBA-HD Apathy & 2.5 & 3.6 & 0.5 & 0.7 & $0.024^{\mathrm{b} *}$ \\
\hline PBA-HD Irritability & 1.85 & 2.35 & 0.65 & 0.67 & $0.039^{\mathrm{b}_{*}}$ \\
\hline PBA-HD Depression & 2.35 & 2.9 & 1.15 & 1.6 & $0.11^{\mathrm{b}}$ \\
\hline \multicolumn{6}{|l|}{ Cognition } \\
\hline MMSE & 29.0 & 1.3 & 29.3 & 1.2 & $0.52^{\mathrm{b}}$ \\
\hline RAVLT A1-A5 & 52.4 & 9.2 & 53.3 & 9.1 & $0.76^{\mathrm{b}}$ \\
\hline RAVLT A7 & 10.7 & 2.39 & 12.15 & 2.18 & $0.052^{\mathrm{b}}$ \\
\hline RAVLT A8 & 13.9 & 1.23 & 14.55 & 1.15 & $0.12^{\mathrm{b}}$ \\
\hline Stroop1 & 44.7 & 8.2 & 44.1 & 7.1 & $0.81^{\mathrm{b}}$ \\
\hline Stroop2 & 58.2 & 12.8 & 56.4 & 9.83 & $0.63^{\mathrm{b}}$ \\
\hline Stroop3 & 86.9 & 17.4 & 86.7 & 17.3 & $0.98^{\mathrm{b}}$ \\
\hline DS forward & 6.5 & 0.9 & 6.4 & 1.3 & $0.67^{\mathrm{b}}$ \\
\hline DS backward & 4.6 & 1.3 & 5.0 & 1.2 & $0.26^{\mathrm{b}}$ \\
\hline BNT & 54.8 & 3.2 & 54.3 & 3.5 & $0.64^{\mathrm{b}}$ \\
\hline TMT A & 29.0 & 1.3 & 29.3 & 1.2 & $0.66^{\mathrm{b}}$ \\
\hline TMT B & 67.6 & 22.7 & 59.8 & 18.6 & $0.25^{\mathrm{b}}$ \\
\hline AVF & 23.7 & 5.4 & 23.6 & 4.3 & $0.92^{\mathrm{b}}$ \\
\hline LVF & 31.6 & 13.5 & 38.5 & 10.1 & $0.074^{\mathrm{b}}$ \\
\hline NART & 86.8 & 5.0 & 91.4 & 5.0 & $0.15^{\mathrm{b}}$ \\
\hline Digit Symbol & 79.5 & 24.7 & 81.3 & 17.5 & $0.79^{\mathrm{b}}$ \\
\hline \multicolumn{6}{|l|}{ VAS } \\
\hline Anger & 61.5 & 16.8 & 72.6 & 18.9 & $0.058^{\mathrm{b}}$ \\
\hline Sad & 67.4 & 19.0 & 78.5 & 18.3 & $0.067^{\mathrm{b}}$ \\
\hline Happy & 75.5 & 15.1 & 76.2 & 13.4 & $0.89^{\mathrm{b}}$ \\
\hline Neutral & 74.4 & 16.9 & 74.4 & 15.9 & $0.99^{\mathrm{b}}$ \\
\hline
\end{tabular}

CAG, number of CAG-repeats; UHDRS_m, Unified Huntington's Disease Rating Scale motor score; 5yPDO, 5 year probability of disease onset; BDI, Beck Depression Inventory; STAI, State-Trait Anxiety Inventory; PBA-HD: Problem Behaviours Assessment for Huntington's Disease; MMSE, Mini Mental-State Examination; RAVLT, Rey Auditory Verbal Learning Test; A1-A5 = the sum of scores on trials A1 to A5 of the RAVLT; A7: Delayed Recall score; A8: Recognition score (difference between the number of correct hits and false hits on the recognition trial); DS: digitspan; BNT, Boston Naming Test; TMT, Trail Making Test; AVF, Animal Verbal Fluency (\# in 1 minute); LVF, letter verbal fluency with \# in 1-minute starting with "N," "A," and "K"; NART: National Adult Reading Test (Dutch version); Digit Symbol: Digit Symbol subtest from Wechsler Adult Intelligence Scale R, VAS, Visual Analogous Scale judgments of intensity of emotion re-experience (0: very low intensity, 100: very high intensity).

abased on 2-sample test for equality of proportions with continuity correction.

${ }^{\mathrm{b}}$ Based on 2-sample $t$-test.

*Significant difference

which they felt sad and finally two events that were not associated with any particular emotion. In line with a previous study, there were no a priori constraints of any kind to the themes or nature of the events [Damasio et al.,
2000]. In addition, participants were instructed to provide a word for each of the eight events so that when the word was shown to them, they would immediately recognize to which event and emotion it referred. 


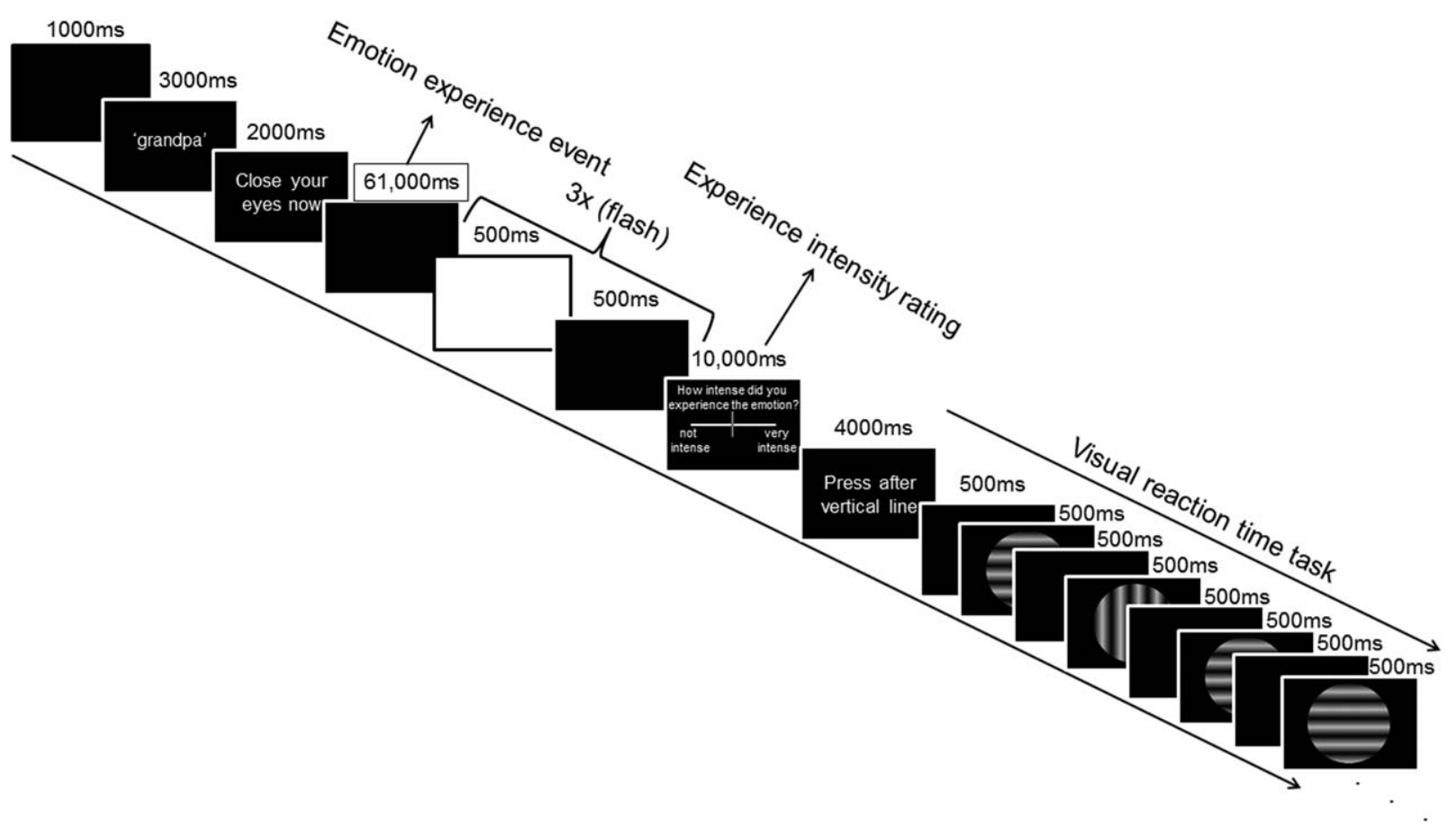

Figure I.

Schematic presentation of the experimental procedure.

The experiment consisted of two runs, each containing four blocks, one for every emotion. The procedure of one block is schematically presented in Figure 1. A block started with a 1,000 ms black screen, followed by a 3,000 ms presentation of one of the words provided by the participant. Next, "Close your eyes now" appeared for 2,000 ms. Subsequently, a blank screen was shown for $61 \mathrm{~s}$. This $61 \mathrm{~s}$ event was the emotion experience event. The end of this interval was signaled to the participant by three alternating $500 \mathrm{~ms}$ presentations of a black and white screen (which were clearly noticeable even with the eyes closed). During the following $10 \mathrm{~s}$, a visual analogous scale was presented on which participants could indicate how intensely they had re-experienced the emotion. Next, the text "Press after vertical line" was presented for 4,000 ms. Subsequently, 30 stimuli consisting of a circle filled with line gratings were serially presented for $500 \mathrm{~ms}$, with a $500 \mathrm{~ms}$ interstimulus interval during which a black screen was presented. These 30 grating stimuli consisted of 5 vertical and 25 horizontal gratings. These grating orientation detection tasks alternated with the emotion experience events to minimize carry-over effects of emotions between emotion experience events.

A practice session immediately preceded the scanning session. The procedure of the practice session was identical to the experimental procedure, except for the duration of the emotion experience event, which lasted 30 instead of $61 \mathrm{~s}$. The participant was instructed to re-experience the respective emotion as intensely as possible during the emotion experience event.
The method of emotion induction through recollection of autobiographical episodes has been proven valuable [Damasio et al., 2000]. We reasoned that it might be beneficial to minimize contamination of subjective experience of different emotions by introducing a clear psychological demarcation episode between emotions. Therefore, we added a nonemotional perceptual task that showed considerable cognitive (attentional) demands as a means to obtain a form of "tabula rasa" of the subjective emotional state. Furthermore, for standardization and follow-up (the postscanning interview, see below) purposes, we included the word selection by the participant that was visually presented in the scanner.

\section{Image Acquisition}

Functional MR imaging was performed using a 3 Tesla MR scanner (Achieva3T; Philips, Best, the Netherlands) with a 32-channel head coil. All participants underwent two runs, each with a duration of 507 s. In each run 140 T2*-weighted Blood-Oxygenation Level Dependent (BOLD) contrast volumes were acquired. A volume consisted of 70 axial slices oriented parallel to the anterior commissure- posterior commissure (AC-PC) plane (slice thickness=2.0 mm; no gap; in-plane resolution $=2.75 \times$ $2.75 \mathrm{~mm}$; matrix size $=80 \times 80$; FOV $=220 \times 220 \mathrm{~mm})$, positioned to cover the whole brain ( $\mathrm{TE}=26$; $\mathrm{TR}=3,500 \mathrm{~ms}$; flip angle $=90^{\circ}$ ), optimized for subcortical sensitivity [Morawetz 
et al., 2008]. Functional runs were preceded by acquisition of four dummy volumes to allow for T1 equilibration. A highresolution T1-weighted anatomical image (voxel size $=1 \times$ $1 \times 1 \mathrm{~mm}$ ) was acquired in between the functional runs, using a three-dimensional (3D) magnetization-prepared-rapid acquisition gradient echo sequence $(\mathrm{TR}=9.6 \mathrm{~ms} ; \mathrm{TE}=4.6 \mathrm{~ms}$; matrix size $=256 \times 256$; 182 slices $)$.

\section{Post-Scanning Semistructured Interview}

Following the scanning session, all participants were interviewed by a physician who was blind regarding the genetic status. The semistructured interview consisted of standardized questions related to the words (and hence the autobiographical emotional episodes) selected by the participant and inquired about the content and chronology of the episode as well as about the re-experience in the scanner. In addition to the subjective ratings during the scanning session, these interviews confirmed that the participants successfully re-experienced the target emotions.

\section{Analysis}

Grey matter volume analyses were performed by means of Voxel-based morphometry using the VBM8 toolbox (http://dbm.neuro.uni-jena.de/vbm) for SPM8 (Wellcome Trust Centre for Neuroimaging, UCL, London, United Kingdom) within MatLab R2008a (Mathworks, Inc). VBM has been reported as a valuable tool to assess subcortical grey matter volume in HD [Douaud et al., 2006]. Preprocessing of T1 structural images included bias correction, segmentation and normalization to MNI space within a unified model, including high-dimensional DARTEL-normalization. Grey matter was modulated by affine and nonlinear components. Modulated images were smoothed using a Gaussian kernel of $8 \mathrm{~mm}$ at FWHM.

Other imaging data were analyzed using BrainVoyager QX 2.8.2 (Brain Innovation, Maastricht, The Netherlands). Preprocessing of the functional data included mean intensity adjustment, slice scan time correction (cubic-spline interpolation), 3D motion correction (trilinear/sinc interpolation), temporal filtering (high pass GLM-Fourier of 2 sines/cosines) and Gaussian spatial smoothing (8 $\mathrm{mm})$. Functional data were coregistered with the anatomical volume and transferred into Talairach (TAL) space. Analysis of cortical activation followed cortex-based intersubject alignment, which minimized interindividual differences in cortical folding pattern by maximizing the spatial correspondence between the individual gyral/sulcal patterns. Noncortical effects were analyzed in subcortical space as defined by a commonly used atlas [Eickhoff et al., 2007] that was adapted for TAL-space. The statistical analysis was based on the General Linear Model in an extended TAL-space, including the cerebellum. Emotion blocks were defined by the $61 \mathrm{~s}$ time interval synchronized with the on- and offset of the blank screen. We performed a paramet- ric single-trial effect coding at subject level in which every emotion block was parametrically modulated by the intensity rating following the respective event. Subsequently, we performed a random effects analysis with the four emotion events and 4 visual reaction time events as within-subject variables and HD genetic status (preHD, Gene-Neg Ctrls) as between subjects factor. The statistical threshold was set at 0.05 (cluster-size corrected following 5,000 Monte-Carlo simulations). Demographic and psychophysical data were analyzed with IBM SPSS Statistics 20 and R.

\section{RESULTS}

\section{Behavioral Results}

Table I shows the demographic, clinical, motor, behavioral and cognitive characteristics of the two study groups. Significant group differences were restricted to the CAGrepeat length and PBA-HD total score as well as the PBAHD subscales apathy and irritability. Probability of disease onset within 5 years (5yPDO) was estimated based on age and CAG repeat length [Langbehn et al., 2004]. This averaged only $11 \%$, indicating that the preHD group was far from a manifest stage. There were no significant group differences in the subjective intensity ratings of emotional experiences during the scanning session, although there was a trend $(P=0.058)$ toward less intense subjective anger experience in the preHD group.

\section{Structural Imaging Results}

Two bilateral clusters in the striatum showed reduced grey matter volume in the preHD group $(P<0.001$, uncorrected; $>70$ voxels). These clusters were located in the head of the caudate nucleus and putamen (See Fig. 2). We pooled the left caudate nucleus cluster with the right caudate cluster and the left putamen cluster with the right. We then calculated the amount of grey matter in the caudate nucleus and putamen clusters for every preHD subject and the Pearson correlation coefficient with the 5yPDO and PBA-HD total and subscale scores. This revealed for both caudate nucleus and putamen significant negative correlations with 5yPDO (caudate: $r(20)=-0.600, P<0.005$; putamen $r(20)=-0.678, P<0.001)$, but no significant correlations with any of the PBA-HD scores.

\section{Functional Imaging Results}

We investigated group differences in anger-selective (anger experience $>$ sad + happy + neutral experience) brain activation between the preHD and Gene-Neg Ctrls group. The results are presented in Figure 3 and Table II. We observed hyperactivation in the preHD group in the right pulvinar, premotor/prefrontal cortex, parieto-occipital sulcus, left pallidum, cerebellum, supramarginal gyrus, superior parietal lobule (SPL), and bilateral anterior and 


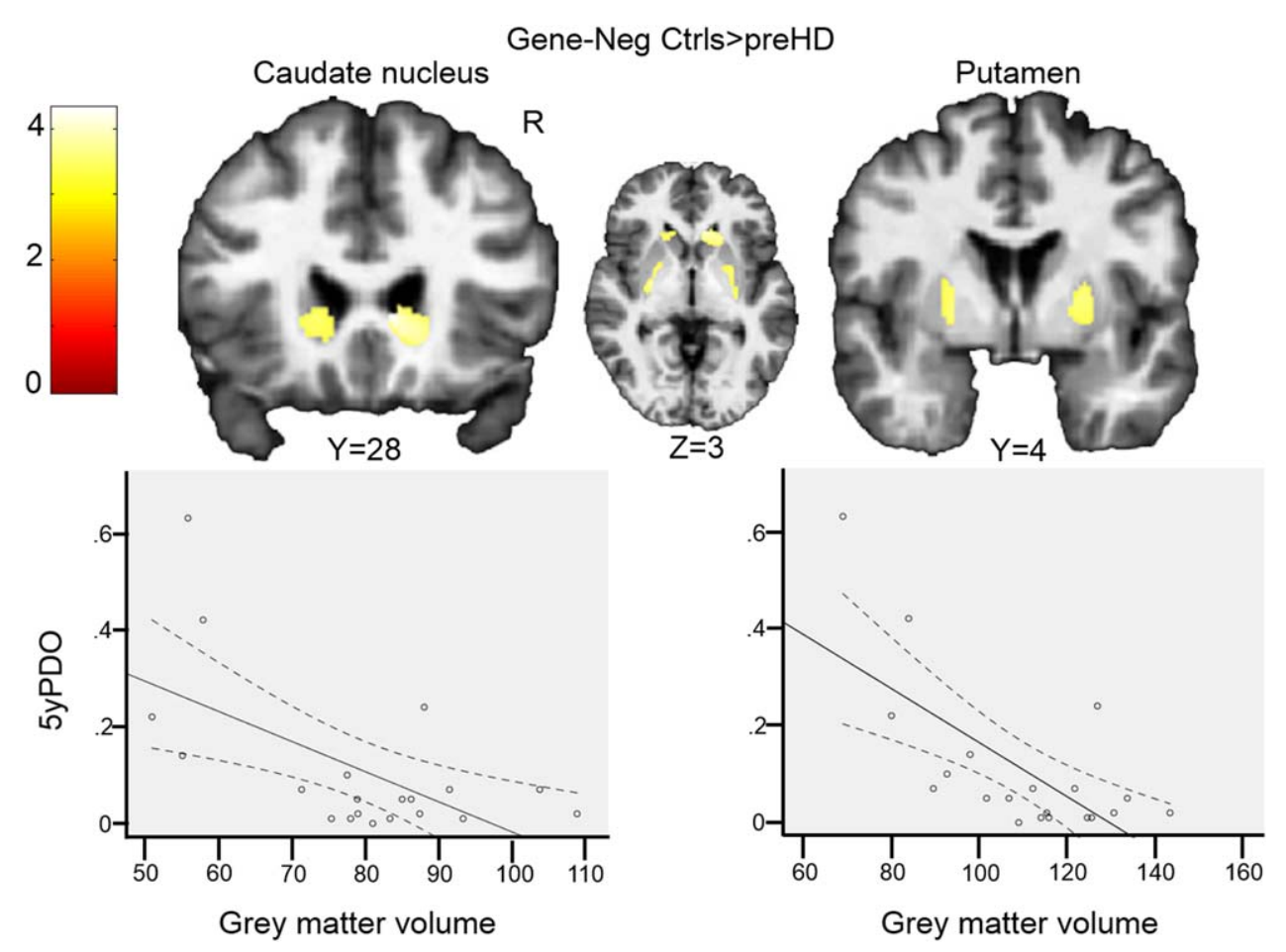

Figure 2.

Structural imaging results. The top row displays the regional subcortical volumetric group differences. The scatterplots below show the correlation with 5-year probability of disease onset. The solid line displays the linear regression fit and the dotted lines indicate the mean $95 \%$ confidence band. The $\mathrm{x}$-axis scale refers to the amount of grey matter within the region demarking the group difference.

posterior cingulate cortex, while we observed hypoactivation in the left amygdala.

\section{Correlations with Structural Results}

Next, we investigated whether anger-selective regional activation changes in the preHD group were associated with striatal atrophy. Therefore, we correlated the individual grey matter volumes of the bilateral head of the caudate nucleus and putamen with the activation magnitude during anger experience. Correlations with peak values are reported. For caudate volume, there was a positive correlation with activation in the left posterior cingulum $(r(20)=0.721, \quad P<0.0003)$ and amygdala $\quad(r(20)=0.506$, $P<0.023)$. For putaminal grey matter volume, there was a positive correlation with amygdalar activation $(r(20)=0.645$, $P<0.002)$ and a negative correlation with pulvinar activation $(r(20)=-0.546, P<0.013)$ (Fig. 3).

\section{Brain-Behavior Correlations}

The association between clinical irritability and anger experience was examined by correlating the PBA-HD Irri- tability scores with the functional MRI (fMRI) activations during anger experience (vs. all other emotions). The results show a positive correlation with pulvinar activation $(r(20)=0.680, P<0.001)$ (Fig. 3).

\section{DISCUSSION}

The main objective was to investigate the neural pathophysiology underlying irritability in carriers of the Huntington mutation before the onset of motor symptoms. The estimated probability of disease onset within 5 years in these preHD subjects averaged only $11 \%$. Nevertheless, the preHD group showed striatal atrophy and increased irritability compared to a control group that faced similar HD-related familial stressors. This result is consistent with previous reports of early presymptomatic structural brain changes and psychiatric features in HD [Aylward et al., 2004; Tabrizi et al., 2013; van Duijn et al., 2007].

The main finding of this study concerns the neural changes in preHD associated with the experience of feelings of anger. The results reveal functional group differences in a distributed set of areas that have been associated with emotion regulation in normal subjects: lateral 


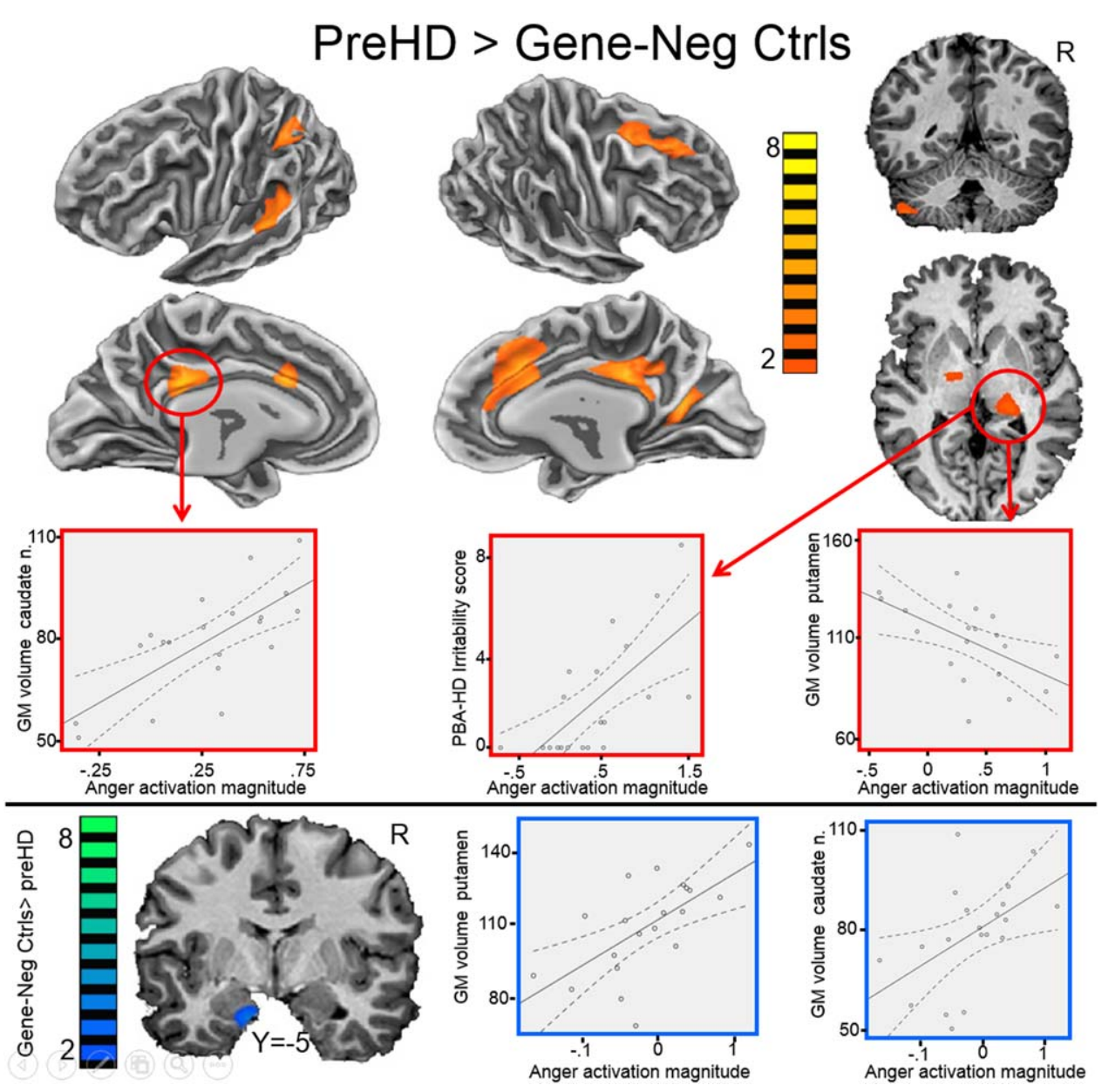

Figure 3.

Functional imaging results. The two top rows display the statistical groups differences (preHD>Gene-Neg Ctrls) during experience of anger emotions (compared to happy, sad and neutral experiences). The third row displays scatterplots of within preHD-group associations between the fMRI parameter estimates and volumetric and behavioral data. The solid line displays the linear regression fit and the dotted lines indicate the mean

cerebellum, pallidum, anterior and posterior cingulate cortex, somatosensory association cortex, pulvinar, and amygdala [Damasio et al., 2000; Denson et al., 2009; Fabiansson et al., 2012; Pawliczek et al., 2013; Vytal and Hamann, 2010]. Mainly, we found that feelings of anger, relative to other emotions and neutral state, in preHD subjects are associated with hyperactivation in the emotion experience neurocircuitry.

Interestingly, the hyperactivation in the ACC falls within the rostral cingulate zone (RCZ). This area forms part of the basal ganglia thalamocortical circuit [Alexander et al., 1986] and receives dopaminergic projections from the substantia nigra. It projects to the dorsal striatum, motor cortices and amygdala [Shackman et al., 2011]. All these areas
$95 \%$ confidence band. The $x$-axis scale refers to the number of grey matter voxels within the region demarking the group difference. The bottom row displays the statistical groups difference (Gene-Neg Ctrls>preHD) during experience of anger emotions (compared to happy, sad and neutral experiences) and scatterplots of the association with volumetric data.

show functional or structural abnormalities in this study. The RCZ is a somatotopically organized premotor area that has been associated with the expression of affect. For instance, direct microstimulation of the monkey RCZ triggers emotional expressions [Shackman et al., 2011]. The human RCZ has also been associated with the experience of affect [Lane et al., 1998] and cognitive control [Shackman et al., 2011]. Remarkably, emotional expressions, experience of affect, and cognitive control are all affected in HD, suggesting a central role of ACC abnormalities in the irritability phenotype.

In addition to the ACC, the thalamic pulvinar seems to play a cardinal role in irritability symptomatology. The pulvinar is also embedded in the basal ganglia 
TABLE II. Structural and functional imaging results

\begin{tabular}{|c|c|c|c|c|c|c|}
\hline & \multirow[b]{2}{*}{$N$ voxels (vertices) } & \multicolumn{3}{|c|}{ Peak TAL coordinate } & \multirow[b]{2}{*}{$T$} & \multirow[b]{2}{*}{$P$} \\
\hline & & $x$ & $y$ & $z$ & & \\
\hline \multicolumn{7}{|l|}{$\begin{array}{l}\text { Structural group differences } \\
\text { (Gene-Neg Ctrls }>\text { preHD) }\end{array}$} \\
\hline Right caudate nucleus & 93 & 19 & 18 & 1 & 3.24 & 0.001 \\
\hline Left caudate nucleus & 309 & -8 & 20 & 0 & 4.16 & 0.0002 \\
\hline Right putamen & 386 & 28 & -12 & -1 & 3.71 & 0.0007 \\
\hline Left putamen & 378 & -28 & -15 & -4 & 3.50 & 0.001 \\
\hline \multicolumn{7}{|l|}{ (preHD>Gene-Neg Ctrls) } \\
\hline \multicolumn{7}{|l|}{ No significant results } \\
\hline \multicolumn{7}{|l|}{$\begin{array}{l}\text { Functional group differences } \\
\text { (preHD>Gene-Neg Ctrls) }\end{array}$} \\
\hline Right Thalamus (pulvinar) & 1,133 & 23 & -29 & 6 & 3.33 & 0.009 \\
\hline Left lenticular nucleus & 431 & -16 & -8 & 6 & 2.81 & 0.007 \\
\hline Left cerebellum & 1,390 & -43 & -44 & -42 & 3.21 & 0.002 \\
\hline \multicolumn{7}{|l|}{ Right cingulate cortex } \\
\hline Anterior & $(511)$ & 11 & 20 & 36 & 3.65 & 0.0007 \\
\hline Posterior & $(670)$ & 4 & -30 & 30 & 3.86 & 0.0004 \\
\hline \multicolumn{7}{|l|}{ Left cingulate cortex } \\
\hline Anterior & (214) & -5 & 16 & 29 & 4.34 & 0.0001 \\
\hline Posterior & (412) & -4 & -33 & 29 & 4.80 & 0.00002 \\
\hline Right POS & $(282)$ & 22 & -57 & 16 & 3.73 & 0.0006 \\
\hline Right SFS & (338) & 2 & 11 & 23 & 3.44 & 0.001 \\
\hline Left STG & (698) & -56 & -34 & 14 & 3.95 & 0.0003 \\
\hline Left SPL & $(568)$ & -30 & -49 & 38 & 2.92 & 0.005 \\
\hline \multicolumn{7}{|l|}{ (Gene-Neg Ctrls>preHD) } \\
\hline Left amygdala & 458 & -16 & -2 & -21 & 3.88 & 0.0003 \\
\hline
\end{tabular}

Gene-Neg Ctrls, Gene-negative control group; preHD, premanifest carriers of Huntington's Disease group; POS, parieto-occipital sulcus; SFS, superior frontal sulcus; STG, superior temporal gyrus; SPL, superior parietal lobule.

thalamocortical circuit [Alexander et al., 1986] and has functionally been associated (besides vision) with emotional experience, particularly feelings of anger [Damasio et al., 2000; Denson et al., 2009; Vytal and Hamann, 2010]. It is noteworthy that all these associations are reflected in the present findings. First, pulvinar activation during anger experience correlated negatively with grey matter volume in the atrophic putamen in the preHD group. Hence, more atrophy at the striatal level of the basal ganglia thalamocortical circuit is accompanied by higher activation at the thalamic level. Second, the pulvinar was more active in the preHD than in the Gene-Neg Ctrls during anger experience. This represents pathology in a node of the normal network of experiencing anger [Damasio et al., 2000]. Third, pulvinar activation correlated with PBA-HD Irritability scores. This is consistent with functional imaging and lesion studies documenting the involvement of the pulvinar in irritability and emotion dysregulation in other neuropsychiatric conditions [Deveney et al., 2013; Dougherty et al., 2004; Lee et al., 2014; Leibenluft, 2011; Liebermann et al., 2013].

Although the earliest structural macroscopic pathology in $\mathrm{HD}$ is observed in the striatum, there is evidence that the thalamus and ACC also show structural and functional neuropathologic changes in the course of HD. Atrophy of the ACC has been documented at the early manifest and even premanifest stage [Hobbs et al., 2011]. Furthermore, the ACC volume correlated with emotion processing measures (facial emotion recognition) and mood, that is, self-reported depression (Beck Depression Inventory score) [Hobbs et al., 2011]. Functional abnormalities of the ACC in preHD have been related to cognitive deficits, that is, response inhibition [Rao et al., 2014]. Regarding the thalamus, there is evidence suggesting an increase in thalamic metabolism at the premanifest stage, followed by a decrease at the transition to the manifest disease stage [Eidelberg and Surmeier, 2011; Feigin et al., 2007; Tang et al., 2013]. Possibly, the initial hyperactivity reflects a compensatory mechanism. The present results are in line with this notion and provide a link with the functional neuroanatomy of anger regulation and neuropsychiatric symptomatology.

In addition, we observed increased activation in the somatosensory cortex in the preHD group. The hyperactive region falls within the somatosensory association cortex in an area that has been associated with awareness of emotions and internal body states [Anders et al., 2004; Damasio, et al., 2000]. This result is thus more compatible with the notion that preHD subjects experience abnormal bodily sensations (feelings) during anger, regardless of 
subjective intensity of the experience. However, it may be that an abnormal experience of bodily sensations hampers their recognition as emotional states [Kloppel et al., 2010]. This notion fits with the reduced activation of the amygdala. The present results also indicate that this amygdalar effect is proportional to both putaminal and caudate grey matter volume.

Taken together, the present evidence indicates that the neural pathophysiology underlying irritability in preHD constitutes a hyperactivation of the neural anger circuitry, in which the ACC and thalamic pulvinar play a central role.

\section{ACKNOWLEDGMENTS}

The authors are particularly grateful to participants for their participation in the study, to S. Van Cauter for advice concerning scanner parameter settings, to A. Boogaerts, J.P. Frijns, and A. Vogels for assistance in recruiting participants, to G. Matthijs for genetic analysis, and to C. Sleurs for assistance in psychophysical data collection. JVdS is a post-doctoral research fellow for FWO-Vlaanderen. W.V. and K.V.L. are Senior Clinical Investigators of the FWO.

\section{REFERENCES}

Alexander GE, Delong MR, Strick PL (1986): Parallel organization of functionally segregated circuits linking basal ganglia and cortex. Annu Rev Neurosci 9:357-381.

Anders S, Birbaumer N, Sadowski B, Erb M, Mader I, Grodd W, Lotze M (2004): Parietal somatosensory association cortex mediates affective blindsight. Nat Neurosci 7:339-340.

Aylward EH, Sparks BF, Field KM, Yallapragada V, Shpritz BD, Rosenblatt A, Brandt J, Gourley LM, Liang K, Zhou H, Margolis RL, Ross CA (2004): Onset and rate of striatal atrophy in preclinical Huntington disease. Neurology 63:66-72.

Beck AT, Ward CH, Mendelson M, Mock J, Erbaugh J (1961): An inventory for measuring depression. Arch Gen Psychiatry 4: 561-571.

Craufurd D, Thompson JC, Snowden JS (2001): Behavioral changes in Huntington Disease. Neuropsychiatry Neuropsychol Behav Neurol 14:219-226.

Damasio A, Carvalho GB (2013): The nature of feelings: Evolutionary and neurobiological origins. Nat Rev Neurosci 14:143-152.

Damasio AR, Grabowski TJ, Bechara A, Damasio H, Ponto LL, Parvizi J, Hichwa RD (2000): Subcortical and cortical brain activity during the feeling of self-generated emotions. Nat Neurosci 3:1049-1056.

de Gelder B, Van den Stock J, de Diego Balaguer R, Bachoud-Levi AC (2008): Huntington's disease impairs recognition of angry and instrumental body language. Neuropsychologia 46:369373.

Denson TF, Pedersen WC, Ronquillo J, Nandy AS (2009): The angry brain: Neural correlates of anger, angry rumination, and aggressive personality. J Cogn Neurosci 21:734-744.

Deveney CM, Connolly ME, Haring CT, Bones BL, Reynolds RC, Kim P, Pine DS, Leibenluft E (2013): Neural mechanisms of frustration in chronically irritable children. Am J Psychiatry 170:1186-1194.
Douaud G, Gaura V, Ribeiro MJ, Lethimonnier F, Maroy R, Verny C, Krystkowiak P, Damier P, Bachoud-Levi AC, Hantraye P, Remy P (2006): Distribution of grey matter atrophy in Huntington's disease patients: A combined ROI-based and voxelbased morphometric study. Neuroimage 32:1562-1575.

Dougherty DD, Rauch SL, Deckersbach T, Marci C, Loh R, Shin LM, Alpert NM, Fischman AJ, Fava M (2004): Ventromedial prefrontal cortex and amygdala dysfunction during an anger induction positron emission tomography study in patients with major depressive disorder with anger attacks. Arch Gen Psychiatry 61:795-804.

Eickhoff SB, Paus T, Caspers S, Grosbras MH, Evans AC, Zilles K, Amunts K (2007): Assignment of functional activations to probabilistic cytoarchitectonic areas revisited. Neuroimage 36: 511-521.

Eidelberg D, Surmeier DJ (2011): Brain networks in Huntington disease. J Clin Investig 121:484-492.

Fabiansson EC, Denson TF, Moulds ML, Grisham JR, Schira MM (2012): Don't look back in anger: Neural correlates of reappraisal, analytical rumination, and angry rumination during recall of an anger-inducing autobiographical memory. Neuroimage 59:2974-2981.

Feigin A, Tang C, Ma Y, Mattis P, Zgaljardic D, Guttman M, Paulsen JS, Dhawan V, Eidelberg D (2007): Thalamic metabolism and symptom onset in preclinical Huntington's disease. Brain 130:2858-2867.

Henley SM, Novak MJ, Frost C, King J, Tabrizi SJ, Warren JD (2012): Emotion recognition in Huntington's disease: A systematic review. Neurosci Biobehav Rev 36:237-253.

Hobbs NZ, Pedrick AV, Say MJ, Frost C, Dar Santos R, Coleman A, Sturrock A, Craufurd D, Stout JC, Leavitt BR, Barnes J, Tabrizi SJ, Scahill RI (2011): The structural involvement of the cingulate cortex in premanifest and early Huntington's disease. Mov Disord 26:1684-1690.

Huntington Study Group (1996): Unified Huntington's disease rating scale: Reliability and consistency. Mov Disord 11:136-142.

Ille R, Holl AK, Kapfhammer HP, Reisinger K, Schafer A, Schienle A (2011): Emotion recognition and experience in Huntington's disease: Is there a differential impairment? Psychiatry Res 188: 377-382.

Julien CL, Thompson JC, Wild S, Yardumian P, Snowden JS, Turner G, Craufurd D (2007): Psychiatric disorders in preclinical Huntington's disease. J Neurol Neurosurg Psychiatry 78: 939-943.

Kloppel S, Stonnington CM, Petrovic P, Mobbs D, Tuscher O, Craufurd D, Tabrizi SJ, Frackowiak RS (2010): Irritability in preclinical Huntington's disease. Neuropsychologia 48:549-557.

Kret ME, Sinke CBA, de Gelder B (2010): Emotion perception and health. In: Nyklicek I, Vingerhoets AJ, Zeelenberg M, editors. Emotion regulation and well-being. New York: Springer.

Lane RD, Reiman EM, Axelrod B, Yun LS, Holmes A, Schwartz GE (1998): Neural correlates of levels of emotional awareness. Evidence of an interaction between emotion and attention in the anterior cingulate cortex. J Cogn Neurosci 10:525-535.

Langbehn DR, Brinkman RR, Falush D, Paulsen JS, Hayden MR, International Huntington's Disease Collaborative Group (2004) A new model for prediction of the age of onset and penetrance for Huntington's disease based on CAG length. Clin Genet 65: 267-277.

Lee SE, Khazenzon AM, Trujillo AJ, Guo CC, Yokoyama JS, Sha SJ, Takada LT, Karydas AM, Block NR, Coppola G, Pribadi M, Geschwind DH, Rademakers R, Fong JC, Weiner MW., Boxer 
AL, Kramer JH, Rosen HJ, Miller BL, Seeley WW (2014) Altered network connectivity in frontotemporal dementia with C9orf72 hexanucleotide repeat expansion. Brain 137:3047-3060.

Leibenluft E (2011): Severe mood dysregulation, irritability, and the diagnostic boundaries of bipolar disorder in youths. Am J Psychiatry 168:129-142.

Liebermann D, Ostendorf F, Kopp UA, Kraft A, Bohner G, Nabavi DG, Kathmann N, Ploner CJ (2013): Subjective cognitiveaffective status following thalamic stroke. J Neurol 260:386-396.

Morawetz C, Holz P, Lange C, Baudewig J, Weniger G, Irle E, Dechent $P$ (2008): Improved functional mapping of the human amygdala using a standard functional magnetic resonance imaging sequence with simple modifications. Magn Reson Imag 26:45-53.

Pawliczek CM, Derntl B, Kellermann T, Gur RC, Schneider F, Habel U (2013): Anger under control: Neural correlates of frustration as a function of trait aggression. PLoS One 8:e78503.

Rao JA, Harrington DL, Durgerian S, Reece C, Mourany L, Koenig K, Lowe MJ, Magnotta VA, Long JD, Johnson HJ, Paulsen JS, Rao SM (2014): Disruption of response inhibition circuits in prodromal Huntington disease. Cortex 58:72-85.

Reedeker N, Bouwens JA, Giltay EJ, Le Mair SE, Roos RA, van der Mast RC, van Duijn E (2012): Irritability in Huntington's disease. Psychiatry Res 200:813-818.

Ross CA, Aylward EH, Wild EJ, Langbehn DR, Long JD, Warner JH, Scahill RI, Leavitt BR, Stout JC, Paulsen JS, Reilmann R, Unschuld PG, Wexler A, Margolis RL, Tabrizi SJ (2014): Huntington disease: natural history, biomarkers and prospects for therapeutics. Nat Rev Neurology 10:204-216.

Shackman AJ, Salomons TV, Slagter HA, Fox AS, Winter JJ, Davidson RJ (2011): The integration of negative affect, pain and cognitive control in the cingulate cortex. Nat Rev Neurosci 12:154-167.

Spielberger CD, Gorsuch RL, Lushene RE (1970): STAI: Manual for the State-Trait Anxiety Inventory. Palo Alto, CA: Consulting Psychologists Press.
Tabrizi SJ, Langbehn DR, Leavitt BR, Roos RA, Durr A, Craufurd D, Kennard C, Hicks SL, Fox NC, Scahill RI, Borowsky B, Tobin AJ, Rosas HD, Johnson H, Reilmann R, Landwehrmeyer B, Stout JC, investigators Track-HD (2009): Biological and clinical manifestations of Huntington's disease in the longitudinal TRACK-HD study: Cross-sectional analysis of baseline data. Lancet Neurol 8:791-801.

Tabrizi SJ, Scahill RI, Owen G, Durr A, Leavitt BR, Roos RA, Borowsky B, Landwehrmeyer B, Frost C, Johnson H, Craufurd D, Reilmann R, Stout JC, Langbehn DR, Investigators TrackHD (2013): Predictors of phenotypic progression and disease onset in premanifest and early-stage Huntington's disease in the TRACK-HD study: Analysis of 36-month observational data. Lancet Neurol 12:637-649.

Tang CC, Feigin A, Ma Y, Habeck C, Paulsen JS, Leenders KL, Teune LK, van Oostrom JC, Guttman M, Dhawan V, Eidelberg D (2013): Metabolic network as a progression biomarker of premanifest Huntington's disease. J Clin Investig 123:4076-4088.

Trinkler I, Cleret de Langavant L, Bachoud-Levi AC (2013): Joint recognition-expression impairment of facial emotions in Huntington's disease despite intact understanding of feelings. Cortex 49:549-558.

van Duijn E, Kingma EM, van der Mast RC (2007): Psychopathology in verified Huntington's disease gene carriers. J Neuropsychiatry Clin Neurosci 19:441-448.

Vonsattel JP (2008): Huntington disease models and human neuropathology: Similarities and differences. Acta Neuropathol 115:55-69.

Vytal K, Hamann S (2010): Neuroimaging support for discrete neural correlates of basic emotions: A voxel-based meta-analysis. J Cogn Neurosci 22:2864-2885.

Wheelock VL, Tempkin T, Marder K, Nance M, Myers RH, Zhao H, Kayson E, Orme C, Shoulson I, Huntington Study Group (2003): Predictors of nursing home placement in Huntington disease. Neurology 60:998-1001. 